\title{
А.О. Машовец
}

\section{АКТУАЛЬНЫЕ ВОПРОСЫ ПРОИЗВОДСТВА СУДЕБНОГО ДОПРОСА В РОССИЙСКОМ УГОЛОВНОМ ПРОЦЕССЕ}

\begin{abstract}
Анализируются порядок и условия проведения судебного допроса в рамках состязательной конщепщии судебного следствия. Особое внимание уделено проблеме допустимости подготовки подлежащего допросу лица к даче показаний. Показано приниипиальное значение для состязательной технологии судебного доказывания необходимости разделения судебных допросов на прямой и перекрестный. Обосновываются предложения по совериенствованию действующего уголовно-прочессуального законодательства.

Ключевые слова: судебный допрос, прямой допрос, перекрёстный допрос, состязательное правосудие, судебное следствие.
\end{abstract}

О судебных допросах, их роли в судебном следствии и в установлении фактов по уголовному делу было немало сказано как процессуалистами [1], так и криминалистами [2. С. 108-111]. Разделяя взгляды тех ученых, которые являются сторонниками состязательной идеологии, мы считаем, что именно следственные действия, проводимые в судебном следствии, являются способами собирания, представления, исследования, оценки и соответственно формирования судебных доказательств. Последние, в свою очередь, служат средствами доказывания юридически значимых фактов, составляющих предмет доказывания.

На наш взгляд, одной из продуктивных дефиниций, разработанной для объяснения сущности судебных допросов (равно как и иных следственных действий), является понятие «судебное средство доказывания», которое было предложено в работах С.И. Коневой. Судебное средство доказывания - это сводная величина, определяемая способностью его элементов в совокупности оказать влияние на формирование внутреннего убеждения судьи о наличии или отсутствии доказываемого факта [3. С. 7, 8, 48]. Согласно концепции С.И. Коневой, получается, что допрос входит в «средство доказывания», причем в системе элементов данного «средства» он выступает творческой, интегрирующей составляющей [Там же. С. 8].

Деконструкция, как и реконструкция, в равной степени важны для создания модели события, которое является предметом познания в суде. Одни судебные допросы являются способом реконструкции (прямой допрос), другие (перекрестный допрос) - средством деконструкции текстовой реальности, создаваемой показаниями.

Верно утверждение о том, что судебные допросы выступают главными средствами формирования судебных фактов, все остальные способы получения, фиксации и передачи суду сообщений от лиц вторичны и «полного» до- 
казательства сформировать не могут, представляя собой в случаях, специально предусмотренных законом, производные доказательства [4. С. 11-12].

Содержание допроса, представляющего собой наиболее распространенный способ использования доказательств, как первоначальных, так и производных, как личных, так и «вещественных» (в широком смысле) [5. С. 122], заключается в постановке вопросов и получении ответов допрашиваемого на поставленные ему участниками доказывания вопросы, т.е. в получении устных сообщений (сведений) о вероятных фактических обстоятельствах (имеющих отношение к делу), и формировании на их основе оснований доводов сторон и внутреннего убеждения судьи в наличии или отсутствии доказываемых фактов [3. С. 90]. В состязательном правосудии судебные допросы, а не оглашение следственных протоколов допросов в суде, должны составлять фактосодержащую основу судебного следствия.

«Средство доказывания» в виде судебного допроса имеет не только информационное, но и предметно-чувственное, психоэмотивное и аргументационное наполнение; оно не просто выступает неким проводником (каналом) сведений от источника (допрашиваемого) к адресату - судье, но является инструментом, используемым активным деятелем, а еще вернее - деятелями (с обеих сторон), которые с его помощью «представляют показания», а затем «исследуют», препарирует его, уточняя смысл сообщения лица, помогая участникам судебного следствия, судье понять смысл сообщения, проинтерпретировать его, оценить полученные данные в системе иных доказательств по делу. «Доказательства всегда являются в «одежде» действий участников судебного следствия». [6. С. 154-159].

Судебный допрос состоит из системы действий сторон и суда, направленных на получение от лица, вызванного в суд для дачи показаний, достоверных сведений об обстоятельствах спорного события, которые имеют вид прямого, перекрестного допросов и дополнительных, повторных допросов. Только судебные допросы позволяют суду устанавливать юридически значимые факты. Через непосредственное восприятие процесса допроса, а тем более участие в постановке вопросов допрашиваемому, снятие некорректных, не относящихся к делу вопросов, суд и участники допроса признают доказанными факты, на которых строят свои доводы и выводы. Правовая организация судебного следствия должна быть максимально приближена к условиям, обеспечивающим свободу слова, естественное развитие диалога, недопущение попыток срыва нормальной речевой коммуникации.

Поскольку судебное следствие носит устный, непосредственный, гласный характер, постольку прямой и перекрестный допросы позволяют представлять и исследовать не только показания, личные доказательства, но и любые доказательства, в отношении содержания которых есть спор и сомнения. И суд, и стороны прибегают к допросам для проверки, дополнения содержания любых доказательств [3. С. 88-91].

Для состязательной технологии судебного доказывания разделение судебных допросов на прямой и перекрестный имеет принципиальное значение, на что обращают внимание ведущие ученые. Так, И.Л. Петрухин главный недостаток современного законодательства, регулирующего судебное следствие, видит в том, что оно не предусматривает перекрестный допрос 
обвиняемого, потерпевшего, свидетелей и передопрос их вызвавшей стороной [20. С. 270-271].

В структуру судебного допроса должна быть заложена матрица состязательности так, чтобы каждая из его частей использовалась стороной при выполнении своей функции, а в совокупности они давали кумулятивный эффект в виде достоверного знания. Судебные допросы - прямой и перекрестный, из которых состоит общая процедура получения личного доказательства, - это средства состязательной борьбы за факты, а в целом судебный допрос - это средство достижения истины [3. С. 8, 9].

Остановимся на одной научно-практической проблеме, связанной с общей регламентацией судебного допроса, а именно: допустимости подготовки подлежащего допросу лица к даче показаний участником процесса, который будет представлять данное доказательство в свою пользу.

Верховным Судом Российской Федерации был сформулирован своего рода запрет на общение прокурора со свидетелями обвинения, в том числе, очевидно, и с потерпевшим, во внепроцессуальной форме перед судебным следствием. Установление такого факта было расценено как проявление прокурором необъективности и стало основанием для отмены приговора суда нижестоящей инстанции [8].

Очевидно, что этот запрет распространяется только на официальных представителей стороны обвинения, а значит, запретить адвокатам проводить «опросы» свидетелей защиты невозможно. Адвокаты проводили, проводят и будут проводить досудебную подготовку своих свидетелей к участию в судебном следствии [9. С. 41, 43-44]. Это законом не запрещено, а наоборот, вытекает из смысла норм, содержащихся в п. 2 ч. 3 ст. 86 УПК РФ, ст. 6 Федерального закона «Об адвокатской деятельности и адвокатуре в Российской Федерации» [10]. Закон позволяет адвокатам проводить опрос лиц с их согласия об известных им обстоятельствах дела, причем как лиц, уже допрошенных органами предварительного следствия и давших показания в пользу обвинения, так и любых иных лиц.

Полагаем, подготовка к представлению своих доказательств суду является закономерным и правомерным действием каждой из сторон. Этим подходом и обусловлено наше предложение по легализации подготовки своих свидетелей каждой из сторон. Мы считаем, что не только адвокат, но и прокуpop, которому поручено поддержание государственного обвинения, вправе встречаться со свидетелями (экспертами) до начала судебного разбирательства для обсуждения вопросов, касающихся выступления в суде этого лица, порядка проведения его допроса. Полагаем, что в рамках этих консультаций участник процесса вправе напомнить свидетелю о данных им показаниях, ознакомить его с фактическими материалами, в которых зафиксированы его сообщения, сделанные в ходе досудебного производства; объяснить предмет судебного допроса и круг вопросов, которые ему будут поставлены в ходе прямого допроса, а также возможных вопросов со стороны противника, определить возможные направления дискредитации личности лица и его показаний и способы противостояния им; разъяснить процессуальные особенности судебного следствия и судебных вопросов, правила поведения в суде и пр. 
Так называемая «подготовка свидетеля» к судебному допросу включает в себя широкий комплекс мероприятий, которые освещались в отечественной литературе [11. С. 240-242], включая меры безопасности, доставку свидетеля в здание суда, его пребывание в суде, организацию допроса в условиях, исключающих визуальное наблюдение свидетеля другими участниками судебного разбирательства (ч. 5 ст. 278 УПК РФ), и пр. [12. С. 9, 10].

Впрочем, все вышесказанное по большей части относится к тактикоорганизационным, а не уголовно-процессуальным аспектам проведения судебных допросов, поэтому далее мы не будем подробно останавливаться на них. В принципиальном плане мы даем положительный ответ на вопрос о том, возможны ли внепроцессуальные контакты прокурора и свидетелей, потерпевших, других участников процесса для решения организационных, тактических вопросов предстоящего судебного следствия. Понятно, что они могут быть предметом перекрестного допроса и могут дискредитировать свидетеля, если выяснится, что имело место навязывание свидетелю показаний, выгодных стороне, и т.п. Подготовка свидетелей - это не метод фальсификации доказательств, а совокупность приемов, направленных на сохранение показаний и их наиболее полное и объективное представление суду и недопущение их искажения под влиянием субъективных факторов, иными словами, это скорее средство, способствующее установлению истины по уголовному делу.

Поэтому мы предлагаем включить в статью, регулирующую общий порядок судебного допроса, норму такого содержания: «Подготовка стороной в деле, в том числе прокурором, своего свидетеля к допросам в суде не является обстоятельством, исключающим допустимость показаний данного свидетеля. Однако противоположная сторона вправе при проведении перекрестного допроса выяснить характер данной подготовки и степень влияния, которое было оказано на формирование показаний допрашиваемого».

Остановимся на некоторых аспектах правового регулирования проведения прямого судебного допроса. Хотя наше законодательство не знает такого следственного действия, по факту в каждом судебном процессе юристы проводят его. В научной литературе имеются определения и характеристики прямого допроса [13. С. 77]. Из анализа источников по данной теме вытекает, что прямой или главный допрос проводится вначале для представления показаний «своего свидетеля». Кто вызвал свидетеля, тот и проводит его первоначальный допрос. Прямой допрос следователя, дознавателя, других должностных лиц органов, участвовавших в досудебном производстве по данному уголовному делу, в том числе проводивших оперативно-розыскную деятельность, а также понятых, статистов, других участников следственных действий, которые вызываются в суд для дачи показаний, должен проводиться обвинителем, если иное не будет определено председательствующим ввиду особых обстоятельств [14. С. 7-8, 110-117].

Показания свидетеля, даваемые им на основном допросе, служат началом процесса формирования судебных фактов. Эти показания должны быть даны в максимально свободной форме без каких-либо попыток оказания давления на допрашиваемого со стороны участников судебного следствия и прежде всего самого допрашивающего. Никто не вправе вмешиваться в прямой до- 
прос, если допрашивающий не нарушает закон и нормы судебной этики, придерживается предмета доказывания. Председательствующий в судебном заседании судья вправе контролировать прямой допрос, как и любой другой судебный допрос. По ходатайству участника судебного следствия или по своей инициативе он вправе снимать недопустимые или не относящиеся к делу вопросы, но также и принимать решение о его прекращении, если придет к выводу о его бесцельности или о противоречии интересам правосудия.

Предметом прямого допроса являются сведения, которые еще не представлялись суду. Субъект доказывания проводит этот допрос, чтобы утвердить свою позицию по делу, соответственно значение этого допроса конструктивное, поэтому в его рамках неуместна, как правило, критика показаний и репутации лица, дающего показания, а также использование приемов и средств, допустимых на перекрестном допросе. И, наконец, самое главное на первоначальном допросе недопустимы наводящие вопросы. Этот запрет объясняется тем, что в первоначальном допросе предметом показаний являются обстоятельства, сведения о которых впервые в судебном заседании сообщаются допрашиваемым, и поэтому важно обеспечить объективность показаний, оградить его от возможной пристрастности допрашивающего. В подобных условиях ставить наводящие вопросы недопустимо, поскольку допрашиваемый превращается из независимого источника сведений в проводника позиции допрашивающего. Так что даже в том случае, когда лицо начинает давать показания против стороны, инициировавшей его явку в суд для дачи показаний, последняя не вправе использовать средства и приемы перекрестного допроса (без разрешения председательствующего).

Вопросы, касающиеся репутации дающего показания, его прошлого, в том числе фактов, негативно характеризующих его, допустимо задавать на перекрестном допросе только в открытой форме.

Перейдем к теме о перекрестном допросе, пожалуй, самой спорной и противоречивой, поскольку перекрестный допрос в суде многими в нашей науке не признается [15. С. 56-58]. Формально основания для отрицания института перекрестного допроса дает российский УПК РФ.

Полагаем, что перекрестный допрос имеет решающее значение для формирования судебных фактов на основе показаний в тех случаях, когда имеет место спор о фактических обстоятельствах, удостоверяемых допрашиваемым, и личные доказательства используются в качестве средства разрешения такового. Признание значимости перекрестного допроса законодателем и правоприменителем, присутствие его в тексте закона является показателем зрелости правового сознания, развитости судебной культуры и совершенства законодательной техники. Следует отметить, что еще доктриной русского уголовно-процессуального права перекрестный допрос был признан в качестве важнейшего элемента системы судебного следствия и судебного доказывания, выступал важнейшей процессуальной гарантией прав подсудимого [16. С. 1-64; 17].

Говоря о нормативной базе перекрестного допроса, нельзя не сказать о том, что ее составляют общепризнанные международно-правовые нормы и принципы. В частности, к ним относится правило, содержащееся в подпункте «d» п. 3 ст. 6 Конвенции о защите прав человека и основных свобод от 4 но- 
ября 1950 г. (с последующими изменениями) [18]. Ограничение права стороны защиты на перекрестный допрос основных свидетелей обвинения квалифицируется ЕСПЧ как существенное ограничение права на защиту от обвинения [19. С. 253-255]. Кроме того, правовые основы перекрестного допроса закреплены и в других международно-правовых актах, содержащих стандарты справедливого уголовного судопроизводства: подпункт «d» п. 3 ст. 6 Всеобщей декларации прав человека [20], подпункт «е» п. 3 ст. 14 Международного пакта о гражданских и политических правах [21]; Правила процедур и доказывания, применяемых органами международной уголовной юстиции, действующими на основании Римского статута Международного уголовного суда [22].

В заключение следует отметить, что некоторые предпосылки к тому, чтобы и в нашем законодательстве появились такого рода нормы, имеются в настоящее время. Как уже указывалось нами ранее, Пленум Верховного Суда Российской Федерации сделал ряд шагов для сближения порядка российского судебного следствия по уголовным делам с европейскими стандартами справедливого судебного разбирательства. В частности, об этом свидетельствуют положения Постановления от 27 июня 2013 г. № 21 «О применении судами общей юрисдикции Конвенции о защите прав человека и основных свобод от 4 ноября 1950 года и Протоколов к ней» [23], а также Постановления от 16 апреля 2013 г. № 11 «О внесении изменений в Постановление Пленума Верховного Суда Российской Федерации от 29 апреля 1996 г. № 1 «О судебном приговоре» [24].

\section{Лuтература}

1. Александров А.С., Гришин С.П., Конева С.И. Перекрестный допрос в суде (объяснение его сущности, принципов и порядка проведения, а также практическое наставление к употреблению). 3-е изд., доп. М.: Юрлитинформ, 2014. 548 с.

2. Столбова А.С. Понятие и психологическая сущность допросов и очных ставок // Вопросы права и проблемы становления гражданского общества в России: сб. науч. статей. Хабаровск: Изд-во Дальневост. юрид. ин-та МВД России, 2009. С. 108-111.

3. Конева С.И. Судебные допросы в уголовном процессе: доказательственное знание и порядок проведения: дис. ... канд. юрид. наук. Омск, 2013. 265 с.

4. Кириллова Н.П. Участие государственного обвинителя в судебном следствии: конспект лекции. СПб., 1997. 20 с.

5. Бостанов Р.A. Использование производных доказательств в уголовном судопроизводстве России: дис. ... канд. юрид. наук. Н. Новгород, 2012. 364 с.

6. Хмельницкая Т.В. К вопросу о содержании понятия «формирование доказательств» по уголовному делу // Проблемы юридической науки в исследованиях докторантов, адъюнктов и соискателей: сб. науч. трудов / под ред. М.П. Полякова, М.А. Пшеничнова. Н. Новгород: Изд-во Нижегор. акад. МВД России, 2012. С. 154-159.

7. Судебная власть / Т.Е. Абова, Е.Б. Абросимова, М.В. Боровский и др.; отв. ред. И.Л. Петрухин. М.: ООО «ТК Велби», 2003. 720 с.

8. Определение Верховного Суда Российской Федерации от 3 июля 2007 г. № 74-о07-23 // URL: http://www.consultant.ru/cons/cgi/online.cgi? $r e q=$ doc\&base $=A R B \& n=52972 \&$ dst $=0 \&$ profile $=0 \& \mathrm{mb}=\mathrm{LAW} \& \mathrm{div}=\mathrm{ARB} \& \mathrm{BASENODE}=\& \mathrm{SORTTYPE}=0 \& \mathrm{rnd}=261745.1511413189 \& \mathrm{ts}=12225114$ $107483532146348602 \&$ SEARCHPLUS $=\% \mathrm{CE} \% \mathrm{EF} \% \mathrm{~F} \% \mathrm{E} 5 \% \mathrm{E} 4 \% \mathrm{E} \% \mathrm{~EB} \% \mathrm{E} \% \mathrm{ED} \% \mathrm{E} 8 \% \mathrm{E} \% 20 \%$ C2\%E5\%F0\%F5\%EE\%E2\%ED\%EE\%E3\%EE\%20\%D1\%F3\%E4\%E0\%20\%D0\%EE\%F1\%F1\%E8\% E9\%F1\%ЕA\%ЕE\%Е9\%20\%D4\%E5\%E4\%E5\%F0\%E0\%F6\%E8\%E8\%20\%EE\%F2\%203\%20\%E8\% $\mathrm{FE} \% \mathrm{~EB} \% \mathrm{FF} \% 202007 \% 20 \% \mathrm{E} 3 . \& \mathrm{SRD}=$ true\#0 (дата обращения: 17.04.2017). 
9. Адвокат в уголовном процессе: учеб. пособие / сост. С.Н. Гаврилова; под ред. П.А. Лупинской. М.: Новый Юрист, 1997. 544 с.

10. Об адвокатской деятельности и адвокатуре в Российской Федерации: Федеральный закон от 31 мая 2002 г. № 63-Ф3 (ред. от 02.06.2016) // URL: http:// www. consultant.ru/cons/cgi/online.cgi?req $=$ doc $\&$ base $=$ LAW\&n $=198926 \&$ fld $=134 \& d s t=1000000001,0 \&$ rnd $=0.7760785528578074 \# 0$ (дата обращения: 17.04.2017).

11. Гришин С.П. Подготовка государственного обвинителя к судебному заседанию // «Черные дыры» в российском законодательстве. 2005. № 3. С. 240-242.

12. Белова Г.Д. Обеспечение прокурором законности и обоснованности поддержания государственного обвинения: лекция. М., 2006. 32 с.

13. Конева С.И. Прямой допрос в уголовном суде // Юридическая наука и практика: Вестник Нижегородской академии МВД России. 2012. № 20. С. 75-78.

14. Кучерук Д.С. Использование результатов оперативно-розыскной деятельности в доказывании по уголовным делам о взяточничестве: дис. ... канд. юрид. наук. Н. Новгород, $2011.321 \mathrm{c}$.

15. Князев С.А. Мнимая состязательность // Российская юстиция. 2006. № 7. С. 56-58.

16. Курс уголовного судопроизводства. Т. 2 / И.Я. Фойницкий; общ. ред., послесл., прим.: А.В. Смирнова. СПб.: Альфа, 1996. 606 с.

17. Фойницякий И.Я. Оправдательные решения присяжных заседателей и меры к их сокращению. СПб., 1879. 64 с.

18. Конвенция о защите прав человека и основных свобод: заключена в г. Риме 04.11.1950 (с изм. от 13.05.2004) // URL: http:/www.consultant.ru/cons/cgi/online.cgi?req=doc\&base= $\mathrm{LAW} \& \mathrm{n}=30222 \& \mathrm{fld}=134 \& \mathrm{dst}=1000000001,0 \& \mathrm{rnd}=0.8947453556310814 \# 0 \quad$ (дата обращения: 17.04.2017).

19. Постановление Европейского суда по делу Лука против Италии (Luca v Italy, Application n o. 33354/96. 27.02.2001); Постановление Европейского суда по делу П.С. против Германии (P. S v. Germany, Application n o. 33900/96 20.12.2001) и др. // Европейская конвенция о правах человека и Европейская социальная хартия: право и практика. М.: Изд-во МНИМП, 1998. $600 \mathrm{c}$.

20. Всеобщая декларация прав человека: принята Генеральной Ассамблеей ООН 10.12.1948 // URL: http://www.consultant.ru/cons/cgi/online.cgi?req=doc\&base=LAW\&n= $120805 \& \mathrm{fld}=134 \& \mathrm{dst}=1000000001,0 \& \mathrm{rnd}=0.10703036821249978 \# 0$ (дата обращения: 17.04.2017).

21. Международный пакт о гражданских и политических правах: принят 16.12.1966 Резолюцией 2200 (XXI) на 1496-м пленарном заседании Генеральной Ассамблеи OOH // URL: http:/www.consultant.ru/cons/cgi/online.cgi?req=doc\&base=LAW\&n=5531\&fld=134\&dst= $1000000001,0 \& \mathrm{rnd}=0.11335612631488257 \# 0$ (дата обращения: 17.04.2017).

22. Римский статут Международного уголовного суда: принят в г. Риме 17.07.1998 Дипломатической конференцией полномочных представителей под эгидой ООН по учреждению Международного уголовного суда // URL: http:// www. consultant.ru/cons/cgi/online.cgi?req=doc;base $=\mathrm{INT} ; \mathrm{n}=4226 \# 0$.

23. О применении судами общей юрисдикции Конвенции о защите прав человека и основных свобод от 4 ноября 1950 года и Протоколов к ней: Постановление Пленума Верховного Суда Российской Федерации от 27 июня 2013 г. № 21 // Российская газета. 05.07.2013. № 145 .

24. О внесении изменения в Постановление Пленума Верховного Суда Российской Федерации от 29 апреля 1996 года № 1 «О судебном приговоре»: постановление Пленума Верховного Суда Российской Федерации от 16.04.2013 № 11 // Российская газета. 2013. 5 июля. № 145 .

Mashovets Asiya O. Ural State law University (Yekaterinburg, Russian Federation)

TOPICAL ISSUES OF JUDICIAL INTERROGATION IN THE RUSSIAN CRIMINAL TRIAL Key words: trial examination, direct examination, cross-examination, adversarial proceedings, court investigation.

The article analyses the order and conditions of conducting trial examinations within the framework of adversarial proceedings. According to the author, trial examination is the main means of for- 
mation of judicial facts. Only trial examinations, but not the announcement of their protocols, allow court to establish legally significant facts. The contents of examination comprises the questions and answers of the interrogated person on the questions put by participants of proof, and formation of the arguments of the parties and internal belief of the judge in the existence or lack of the proved facts. A judge recognizes the proved facts through direct perception of the interrogation process, participation in putting questions, disallowing incorrect, irrelevant questions, and builds his conclusions on these facts. Legal organization of judicial examination has to be as close as possible to the conditions, which guarantee freedom of speech, natural development of dialogues, prevention of attempts to ruin normal speech communication.

Judicial examination is preceded by training of the interrogated person who will submit evidence in his favor. The Supreme Court of the Russian Federation has formulated some kind of prohibition against communication of prosecutor with the witnesses of prosecution and the victim, outside of the courtroom before judicial examination. At the same time, the prohibition for lawyers to communicate with their defendants and witnesses would be unreasonable and illegal. Obviously, a lawyer has to explain his witnesses and the client the line of conduct before they start testifying during the trial.

Thus, there is every indication that adversarial proceedings are violated. The lawyer has the rights but a public prosecutor does not have them. The importance of preparation for judicial examination of prosecution witnesses is also obvious in view of anticipation of "attack" of the lawyer on the prosecution witnesses in court, attempts to deny his testimony using illegal or unethical methods. Therefore, references of supporters of legalization of prosecution activities in the sphere of witnesses' preparation for judicial examination to the institute of safety of trial participants, which includes the norms of federal legislation, are quite justified. Taking into account the above information, the author suggests making such amendments to legislation, which would legalize and regulate the order of training of witnesses for testifying.

The author shares a position of many scientists and practicians who recognize the fundamental value of cross-examination for the establishment of facts during judicial examination. It is noted that in our country the Supreme Court of the Russian Federation has accepted a number of decisions, which created prerequisites for such norms to be entrenched in our legislation.

\section{References}

1. Aleksandrov, A.S., Grishin, S.P. \& Koneva, S.I. (2014) Perekrestnyy dopros v sude (ob"yasnenie ego sushchnosti, printsipov i poryadka provedeniya, a takzhe prakticheskoe nastavlenie $k$ upotrebleniyu) [Cross-examination in court (explanation of its nature, principles and procedure as well as practical instruction for use)]. 3rd ed. Moscow: Yurlitinform.

2. Stolbova, A.S. (2009) Ponyatie i psikhologicheskaya sushchnost' doprosov i ochnykh stavok [Concept and psychological essence of interrogations and face-to-face interrogations]. In: Osadchiy, A.A. (ed.) Voprosy prava i problemy stanovleniya grazhdanskogo obshchestva v Rossii [Problems of Law and Formation of Civil Society in Russia]. Khabarovsk: Far East Law Institute of Mistry of Interior of the Russian Federation. pp. 108-111.

3. Koneva, S.I. (2013) Sudebnye doprosy v ugolovnom protsesse: dokazatel'stvennoe znanie $i$ poryadok provedeniya [Judicial interrogations in criminal proceedings: Evidential knowledge and procedure]. Law Cand. Diss. Omsk.

4. Kirillova, N.P. (1997) Uchastie gosudarstvennogo obvinitelya v sudebnom sledstvii [Participation of the public prosecutor in the judicial investigation]. St. Petersburg: [s.n.].

5. Bostanov, R.A. (2012) Ispol'zovanie proizvodnykh dokazatel'stv v ugolovnom sudoproizvodstve Rossii [Derivative evidence in the Russian criminal procedure]. Law Cand. Diss. Nizhny Novgorod.

6. Khmelnitskaya, T.V. (2012) K voprosu o soderzhanii ponyatiya «formirovanie dokazatel'stv» po ugolovnomu delu [On the concept "formation of evidence" in the criminal case]. In: Polyakov, M.P. \& Pshenichnov, M.A. (eds) Problemy yuridicheskoy nauki v issledovaniyakh doktorantov, ad"yunktov $i$ soiskateley [Problems of juridical science in the research of doctoral students, adjuncts and candidates]. Nizhny Novgorod: Nizhny Novgorod Academy of Ministry of Interior of the Russian Federation. pp. 154-159. 
7. Abova, T.E., Abrosimova, E.B., Borovskiy, M.V. et al. (2003) Sudebnaya vlast' [Judicial Power]. Moscow: TK Velbi.

8. Russian Federation. (2007) Decision No. 74-o07-23 of the Supreme Court of the Russian Federation of July 3, 2007. [Online] Available from: http://www.consultant.ru/ cons/cgi/ online.cgi?req=doc;base $=\mathrm{ARB} ; \mathrm{n}=52972$. (Accessed: 17th April 2017). (In Russian).

9. Lupinskaya, P.A. (ed.) (1997) Advokat v ugolovnom protsesse [Counsel for the Defense in the criminal process]. Moscow: Novyy Yurist.

10. Russian Federation. (2002) On advocacy in the Russian Federation: Federal Law No. 63-FZ of May 31, 2002 (as amended on June 2, 2016). [Online] Available from: http://www. consultant.ru/document/cons_doc_LAW_36945/. (Accessed: 17th April 2017). (In Russian).

11. Grishin, S.P. (2005) Podgotovka gosudarstvennogo obvinitelya k sudebnomu zasedaniyu [Preparation of the public prosecutor for the court session]. "Chernye dyry" $v$ rossiyskom zakonodatel'stve - Black Holes in Russian Legislation. 3. pp. 240-242.

12. Belova, G.D. (2006) Obespechenie prokurorom zakonnosti i obosnovannosti podderzhaniya gosudarstvennogo obvineniya [Provision of the prosecutor's legality and validity of public prosecution]. Moscow: [s.n.].

13. Koneva, S.I. (2012) Pryamoy dopros v ugolovnom sude [Direct questioning in a criminal court]. Yuridicheskaya nauka i praktika: Vestnik Nizhegorodskoy akademii MVD Rossii. 20. pp. 7578.

14. Kucheruk, D.S. (2011) Ispol'zovanie rezul'tatov operativno-rozysknoy deyatel'nosti v dokazyvanii po ugolovnym delam o vzyatochnichestve [Using the results of operative-search activity in proving in criminal cases on bribery]. Law Cand. Diss. Nizhny Novgorod.

15. Knyazev, S.A. (2006) Mnimaya sostyazatel'nost' [Imaginary adversariality]. Rossiyskaya yustitsiya - Russian Justitia. 7. pp. 56-58.

16. Foynitskiy, I.Ya. (1996) Kurs ugolovnogo sudoproizvodstva [Criminal Justice]. Vol. 2. St. Petersburg: Al'fa.

17. Foynitskiy, I.Ya. (1879) Opravdatel'nye resheniya prisyazhnykh zasedateley $i$ mery $k i k h$ sokrashcheniyu [Verdict of acquittals of the jurors and measures to reduce them]. St. Petersburg: Tip. Pravitel'stvuyushchego senata.

18. Convention for the Protection of Human Rights and Fundamental Freedoms: concluded in Rome on 04.11.1950 (as amended on May 13, 2004). [Online] Available from: http:// www.consultant.ru/document/cons_doc_LAW_29160/. (Accessed: 17th April 2017). (In Russian).

19. Gomien, D., Harris, D. \& Zwaak, K. (1998) Evropeyskaya konventsiya o pravakh cheloveka $i$ Evropeyskaya sotsial'naya khartiya: pravo i praktika [The European Convention on Human Rights and the European Social Charter: law and practice]. Translated from English. Moscow: MNIMP.

20. UNO. (1948) Vseobshchaya deklaratsiya prav cheloveka: prinyata General'noy Assambleey OON 10.12.1948 [Universal Declaration of Human Rights: adopted by the UN General Assembly on December 10, 1948]. [Online] Available from: http://www. consultant.ru/document/ cons doc_LAW_120805/. (Accessed: 17th April 2017).

21. UNO. (1966) International Covenant on Civil and Political Rights: adopted on December 16, 1966, by Resolution 2200 (XXI) at the 1496th plenary meeting of the UN General Assembly. [Online] Available from: http://www.consultant.ru/document/cons_doc_LAW_5531/. (Accessed: 17th April 2017). (In Russian).

22. UNO. (1998) Rome Statute of the International Criminal Court: adopted in Rome on 17.07.1998 by the United Nations Diplomatic Conference of Plenipotentiaries on the Establishment of an International Criminal Court. [Online] Available from: http:// www.consultant.ru/ cons/cgi/online.cgi?req=doc;base $=I N T ; n=4226 \# 0$. (Accessed: 17th April 2017). (In Russian).

23. Supreme Court of the Russian Federation. (2013a) O primenenii sudami obshchey yurisdiktsii Konventsii o zashchite prav cheloveka i osnovnykh svobod ot 4 noyabrya 1950 goda i Protokolov k ney: Postanovlenie Plenuma Verkhovnogo Suda Rossiyskoy Federatsii ot 27 iyunya 2013 g. № 21 [On general jurisdiction court application of the Convention for the Protection of Human Rights and Fun- 
damental Freedoms of November 4, 1950, and its Protocols: Decree No. 21 of the Plenum of the Supreme Court of the Russian Federation of June 27, 2013]. Rossiyskaya gazeta. 5th July 2013.

24. Supreme Court of the Russian Federation. (2013b) O vnesenii izmeneniya v Postanovlenie Plenuma Verkhovnogo Suda Rossiyskoy Federatsii ot 29 aprelya 1996 goda № 1 "O sudebnom prigovore”: postanovlenie Plenuma Verkhovnogo Suda Rossiyskoy Federatsii ot 16.04.2013 № 11 [On amending the Resolution of the Plenum of the Supreme Court of the Russian Federation of April 29, 1996 No. 1 "On the Court Verdict": Resolution No. 11 of the Plenum of the Supreme Court of the Russian Federation of April 16, 2013]. Rossiyskaya gazeta. 5th July. 